\title{
Type A aortic dissection with associated anomaly of the carotid and vertebral vessels
}

\author{
Niv Ad, MD, Patricia Lee, MD, and James L, Cox, MD, Washington, DC
}

$\mathrm{T}$ he anatomy of the aortic arch may play a critical role in determining the appropriate surgical technique to be used for the emergency treatment of patients with type A dissection of the thoracic aorta. ${ }^{1,2}$ Approximately $80 \%$ of the population has the normal 3-vessel aortic arch. ${ }^{3,4}$ The most common variation (11\%) from the usual anatomy is a 2-vessel arch, known as "common origin of the carotid arteries," (COCA) in which the left common carotid artery arises from the innominate artery, leaving only 2 branches originating from the aortic arch. ${ }^{4,5}$ This pattern clearly results from slower growth of the ventral aortic roots between arches III and IV, allowing fusion between the innominate artery and the left common carotid artery. In COCA, the vertebral arteries usually arise normally from their respective subclavian arteries. ${ }^{6,7}$ The vertebral artery develops in the embryo as a longitudinal channel connecting the cranial intersegmental arteries and is, therefore, usually a branch of the subclavian artery. Incorporation of the proximal left seventh intersegmental artery into the developing aorta results in the left vertebral artery arising directly from the aortic arch. ${ }^{4}$ In the present case of type A dissection in the presence of COCA, the left vertebral artery arose directly from the aortic arch and was markedly dilated and enlarged. This variation of COCA actually resulted in the anomalous left vertebral artery protecting the left side of the brain from ischemia that might have developed as a result of the type A dissection that involved and nearly occluded the anomalous carotid arteries.

\section{Clinical Summary}

A 43-year-old man who had tested positive for human immunodeficiency virus, as well as syphilis and hepatitis $\mathrm{C}$, came to Georgetown University Hospital with acute onset of chest pain

\footnotetext{
From the Department of Thoracic and Cardiovascular Surgery, Georgetown University Medical Center, Washington, DC.

Received for publication April 4, 2000; accepted for publication Nov 8, 2001.

Address for reprints: Niv Ad, MD, Cardiothoracic Surgery Department, Hadassah University Hospital, Jerusalem il-91120, Israel (E-mail: nivadmd@hotmail.com).

J Thorac Cardiovasc Surg 2002;123:570-1

Copyright $\odot 2002$ by The American Association for Thoracic Surgery

$0022-5223 / 2002 \$ 35.00+0 \quad \mathbf{1 2 / 5 4 / 1 2 1 6 7 3}$

doi: $10.1067 / \mathrm{mtc} .2002 .121673$
}

radiating to the posterior part of the neck. Pertinent physical findings included a blood pressure in the right arm that was $40 \mathrm{~mm} \mathrm{Hg}$ less than in the left arm, a grade 4/6 diastolic murmur consistent with aortic insufficiency, and normal results on the neurologic examination.

Emergency studies, including a transesophageal echocardiogram and a thoracic aortogram, disclosed a type A dissection of the thoracic aorta with severe aortic valve insufficiency. The patient was also found to have COCA from the innominate artery and a large dilated left vertebral artery originating directly from the aortic arch. Both the left and right common carotid arteries were involved in the dissection with severe compromise of blood flow especially to the left common carotid artery (Figure 1).

The patient underwent a successful emergency Bentall procedure with the use of a composite graft with a 31-mm mechanical valve and had an uneventful postoperative course. The surgical procedure restored equal blood pressure to the arms, and the patient remained neurologically intact postoperatively.

\section{Discussion}

Type A aortic dissection leads to distal vascular complications in approximately one third of patients by thrombus formation, by discharge of embolic debris, by intussusception of a detached intima, or because of impedance of blood flow in the true lumen caused by the encroachment of the false lumen. Depending on the site of arterial occlusion, compromised blood flow resulting from the dissection may lead to stroke, limb ischemia, renal failure, mesenteric infarction, or other solid organ infarction. Stroke occurs in approximately $7 \%$ of patients with type A dissection, most commonly as a result of carotid artery occlusion. ${ }^{5,8}$ Indeed, one study found that $85 \%$ of all dissection-related strokes resulted from carotid artery occlusion and that all strokes occurring in association with type A dissections resulted from carotid artery occlusion. Stroke associated with type A dissections is a strong predictor of late mortality and morbidity and is associated with poor long-term prognosis., ${ }^{9,10}$

Our patient had a rare combination of neck vessel anomalies and type A aortic dissection (Figure 1) that has not been reported previously. His aortic dissection extended into both common carotid arteries and nearly occluded the left common carotid artery that originated from the innominate artery. However, the dissection did not involve the large left vertebral artery that arose directly from the aorta. Although the left common carotid artery was nearly occluded and the right common carotid artery was severely compromised, the patient had no preoperative neurologic defects, suggesting that the large left vertebral artery played a protective role 


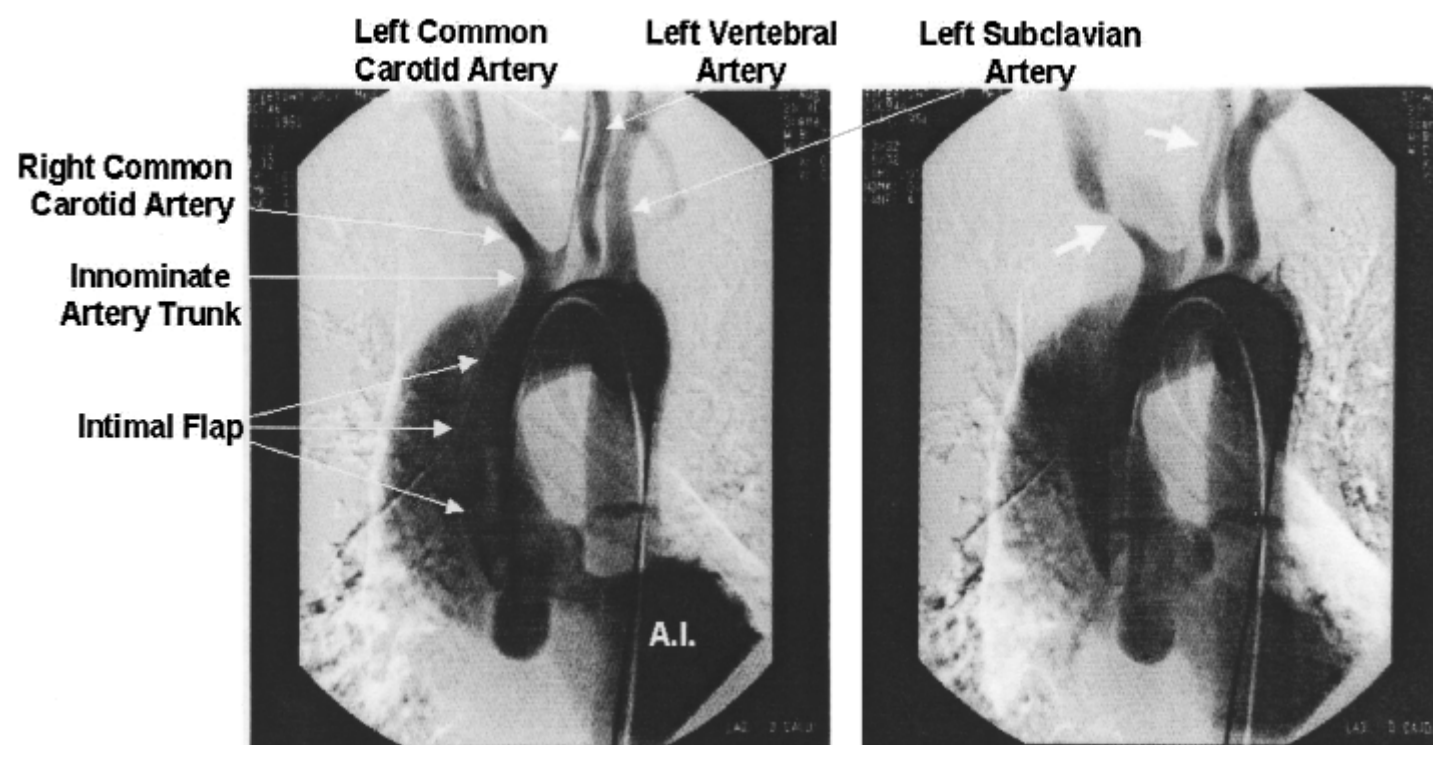

Figure 1. Type A aortic dissection with associated anomaly of the neck vessels. Al, Aortic insufficiency. Right panel, Intimal flap extended to the innominate artery trunk (lower arrow) and to the left common carotid artery (upper arrow).

in this unique combination of congenital anomalies and acquired disease of the thoracic aorta.

The question arises as to why the left vertebral artery was so enlarged, and we have no answer. Clearly, one possibility is that because of the specific set of congenital anomalies (COCA with origin of the left vertebral artery directly from the aorta), the left common carotid artery did not supply as much of the brain as it normally does and the vertebral artery was enlarged to compensate for that deficiency in carotid artery flow. Regardless of the explanation for the enlarged left vertebral artery, it is important to know that this combination of anomalies can be encountered in the presence of type A dissection of the thoracic aorta and that its treatment is the same as that for the normal 3-vessel configuration of the aortic arch.

\section{References}

1. Coselli JS, LeMaire SA, Walkes JC. Surgery for acute type A dissection. Operative Tech Thorac Cardiovasc Surg. 1999;4:13-32.
2. Moon MR, Miller DC. Aortic arch replacement for dissection. Operative Tech Thorac Cardiovasc Surg. 1999;4:33-57.

3. Grande NR, Costa E, Silva A, Pereira AS, Aguas AP. Variations in the anatomical organization of the human aortic arch: a study in a Portuguese population. Bull Assoc Anat. 1995;79:19-22.

4. Nelson ML, Sparks CD. Unusual aortic arch variation: distal origin of common carotid arteries. Clin Anat. 2001;14:62-5.

5. Wells TR, Landing BH, Shankle WR. Syndromal associations of common origin of the carotid arteries. Pediatr Pathol. 1993;13:203-12.

6. Matula C, Trattnig S, Tschabitscher M, Day JD, Koos WT. The course of the prevertebral segment of the vertebral artery: anatomy and clinical significance. Surg Neurol. 1997;48:125-31.

7. Vorster W, du Plooy PT, Meiring JH. Abnormal origin of internal thoracic and vertebral arteries. Clin Anat. 1998;11:33-7.

8. Cambria RP, Brewster DC, Gertler J, Moncure AC, Gusberg R, Tilson $\mathrm{MD}$, et al. Vascular complications associated with spontaneous aortic dissection. J Vasc Surg. 1988;7:199-209.

9. Safi HJ, Miller CC 3rd, Reardon MJ, Iliopoulos DC, Letsou GV, Espada R, et al. Operation for acute and chronic aortic dissection: recent outcome with regard to neurologic deficit and early death. Ann Thorac Surg. 1998;66:402-11.

10. Fann JI, Smith JA, Miller DC, Mitchell RS, Moore KA, Grunkemeier G, et al. Surgical management of acute aortic dissection complicated by stroke. Circulation. 1989;80(3 Pt 1):I-257-63. 